\title{
Volumetric analysis of hand, reciprocating and rotary instrumentation techniques in primary molars using spiral computed tomography: An in vitro comparative study
}

\author{
Ganesh Jeevanandan ${ }^{1}$, Eapen Thomas ${ }^{2}$
}

Correspondence: Dr. Ganesh Jeevanandan

Email: helloganz@gmail.com

\begin{abstract}
'Department of Paediatric and Preventive Dentistry, Saveetha Dental College and Hospitals, Saveetha University, Chennai, Tamil Nadu, India,

2Department of Paedodontia, Dr. Sunny Medical Centre, Sharjah, UAE
\end{abstract}

\section{ABSTRACT}

Objective: This present study was conducted to analyze the volumetric change in the root canal space and instrumentation time between hand files, hand files in reciprocating motion, and three rotary files in primary molars. Materials and Methods: One hundred primary mandibular molars were randomly allotted to one of the five groups. Instrumentation was done using Group I; nickel-titanium (Ni-Ti) hand file, Group II; Ni-Ti hand files in reciprocating motion, Group III; Race rotary files, Group IV; prodesign pediatric rotary files, and Group V; ProTaper rotary files. The mean volumetric changes were assessed using pre- and post-operative spiral computed tomography scans. Instrumentation time was recorded. Statistical analysis to access intergroup comparison for mean canal volume and instrumentation time was done using Bonferroni-adjusted Mann-Whitney test and Mann-Whitney test, respectively. Results: Intergroup comparison of mean canal volume showed statistically significant difference between Groups II versus IV, Groups III versus V, and Groups IV versus V. Intergroup comparison of mean instrumentation time showed statistically significant difference among all the groups except Groups IV versus V. Conclusion: Among the various instrumentation techniques available, rotary instrumentation is the considered to be the better instrumentation technique for canal preparation in primary teeth.

Key words: Nickel-titanium flex files, primary teeth, rotary files

\section{INTRODUCTION}

The specialty of endodontics has evolved over the years. The modern endodontic practice has little resemblance to the traditional practice. ${ }^{[1]}$ The fundamental objective of pediatric dentistry is to preserve a primary tooth within the dental arch until normal exfoliation. ${ }^{[2]}$ Among the various

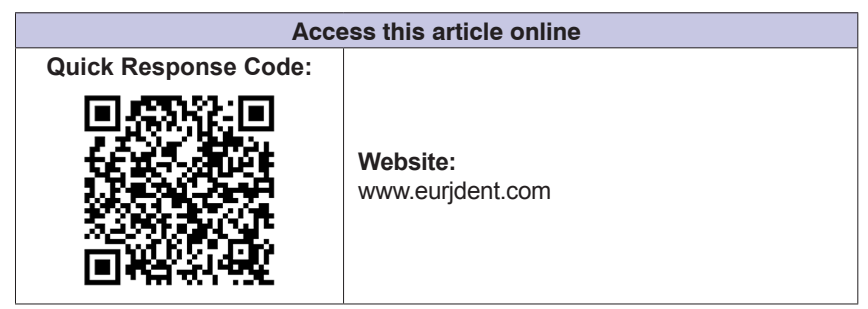

treatment modalities for restoring a primary tooth, the pulpectomy procedure is the preferred treatment of choice for a grossly infected tooth. ${ }^{[3]}$ Pulpectomy in a primary tooth aims at total debridement of the pulpal space by chemomechanical instrumentation. ${ }^{[4,5]}$ The endodontic procedure in primary teeth was first

This is an open access article distributed under the terms of the Creative Commons Attribution-NonCommercial-ShareAlike 3.0 License, which allows others to remix, tweak, and build upon the work non-commercially, as long as the author is credited and the new creations are licensed under the identical terms.

For reprints contact: reprints@medknow.com

How to cite this article: Jeevanandan G, Thomas E. Volumetric analysis of hand, reciprocating and rotary instrumentation techniques in primary molars using spiral computed tomography: An in vitro comparative study. Eur J Dent 2018;12:21-6.

DOI: 10.4103/ejd.ejd_247_17 
reported in 1953 by Rabinowitch. ${ }^{[6]}$ Conventionally, root canal instruments were manufactured using carbon steel and then replaced by stainless steel. ${ }^{[7]}$ Root canal instrumentation with hand files is associated with iatrogenic errors such as ledging, canal transportation, zipping, and apical blockage. Thus, nickel-titanium (Ni-Ti) files were introduced for root canal preparation. ${ }^{[8-10]}$

In the mid-90s, research started regarding the use of Ni-Ti files during pulp therapy in primary teeth. In 2000, Barr et al. first described the use of $\mathrm{Ni}-\mathrm{Ti}$ rotary files during endodontic procedure in primary teeth. ${ }^{[4]}$ Although the debris is effectively removed, the retrieval of the fractured instrument within the root canal of primary teeth is a strenuous procedure. Later, the $90^{\circ}$ horizontal reciprocating motion was substituted for rotation, thereby, reducing the torsional stress and cyclic fatigue of $\mathrm{Ni}$-Ti instruments. ${ }^{[11]} \mathrm{Ni}-\mathrm{Ti}$ instruments are safer when used with a reciprocating movement than when used in continuous rotation. ${ }^{[12]}$ However, apart from its debridement ability, there is little information on the shaping capability of this reciprocating motion for root canal preparation. ${ }^{[13]}$ Spiral computed tomography (SCT) has been used to evaluate the shaping ability of the instruments after root canal preparation. ${ }^{[14,15]}$ Hence, this in vitro study aimed at comparing the root canal preparation, instrumentation time, and incidence of lateral perforation in primary molars instrumented with manual $\mathrm{Ni}$-Ti files, $\mathrm{Ni}$-Ti files in reciprocating motion, and three types of rotary files using SCT scan.

\section{MATERIALS AND METHODS}

The current study was conducted in the Department of Paedodontics and Preventive Dentistry in a Dental College. The study design was approved by the Institutional Review Board.

\section{Selection of teeth}

Human primary mandibular first and second molars were collected from rural public health centers run by the Government of Tamil Nadu, India, where extraction is the only treatment available for symptomatic primary teeth. Primary teeth extracted before orthodontic treatment retained teeth beyond the age of exfoliation were also included in the study. Occupational safety and health administration guidelines and regulations for collection, storage, and sterilization of extracted teeth were followed during the study. ${ }^{[14]}$ Inclusion criteria primary teeth with at least two-third of intact root or minimum root length of eight millimeters were included in the study. Primary teeth with developmental defects, evidence of extensive internal/ external root resorption or less than two-third of intact root were excluded from the study.

\section{Sample selection and randomization}

The study sample size was derived from a previous in vitro study with $95 \%$ power using G Power analysis. ${ }^{[16]} \mathrm{A}$ total of 100 primary mandibular molars consisting of 20 teeth per group was randomly allotted to one of the five groups.

\section{Preparation of teeth}

The selected teeth were instrumented by single investigator who was experienced in using manual, reciprocating, and rotary instrumentation techniques. Access opening was done using No. 330 Pear shaped bur (Mani, Tochigi, Japan) in high-speed airotor handpiece (Nsk, Pana Air, Japan). The cementoenamel junction (CEJ) was marked, and the mesial surface of each sample was labeled as " $\mathrm{M}$ " using blue color water - proof permanent marker for identification. The samples were then decoronated at the (CEJ) with diamond disks (No. 133622 DTS, India) and micromotor (Marathon-3 plus +, India) under continuous saline spray.

\section{Mounting of samples for computed tomography and preoperative volume analysis}

The samples of Group 1-5 were mounted in vinyl polysiloxane impression material template (Express ${ }^{\mathrm{TM}}$ XT Putty Quick, 3M ESPE Germany) and were arranged by placing the mesial surface on the right side so as to maintain uniformity in all samples [Figure 1]. The samples were then subjected to light speed plus SCT scanner (GE Electricals, Wilwaukee, USA) in axial, coronal, and sagittal plane by an experienced operator. Volume rendering and multiple planar volume reconstruction for root canal

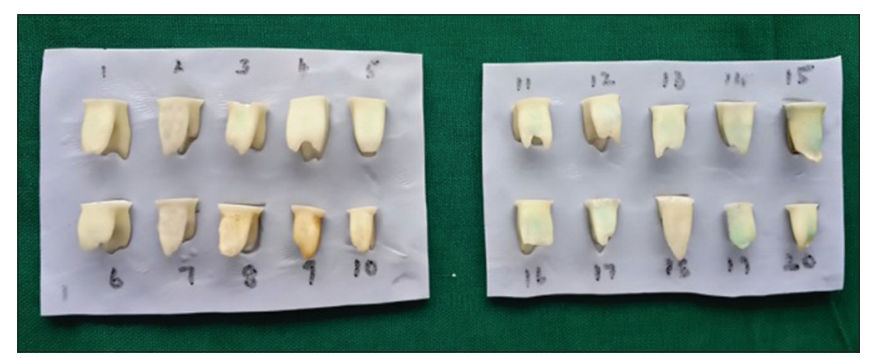

Figure 1: Arrangement of samples in vinyl polysiloxane impression material template for spiral computerized tomography scanning 
measurement were done using Advantage Windows Workstation Version V (GE System, Milwaukee, WI, USA). A constant thickness of $0.65 \mathrm{~mm}$ per slice and a constant spiral or table speed of 0.75 and $120 \mathrm{KVP}$ was used. The volume of all the samples was calculated from the canal orifice to $1 \mathrm{~mm}$ short of apical foramen.

\section{Root canal instrumentation}

The thinnest of root canals were taken for root canal preparation, namely, mesiolingual root canal in mandibular first and second molar. The working length of the canal to be prepared of all samples were measured by introducing No. 10 size stainless Steel K-files file into canal until the file was just visible at the apical foramen. The working length was established by subtracting $1 \mathrm{~mm}$ from visible length. Glide path was established by No. 10 size K-file (Mani, Tochigi, Japan) in all the samples. During instrumentation, Ethylenediaminetetraacetic acid (RC Help, Prime Dental Products Pvt Ltd, Thane, India) and saline was used as lubricant and irrigating solution. The instrumentation time was recorded in seconds using stopwatch.

- Group I: The root canals were circumferentially instrumented from No. 15 Ni-Ti K-flex file to No. 30 Ni-Ti K-flex file (Mani, Tochigi, Japan)

- Group II: The root canals were instrumented using No. 15 Ni-Ti K-file to No. 30 Ni-Ti K-flex file, which was coupled with NSK Endodontic contra-angle Reciprocating hand piece (TEP-ER10, Japan)

- Group III: RaCe size 20, 4\% taper rotary file (FKG Switzerland) was used till the working length using an X-Smart motor (Dentsply India Pvt. Ltd., Delhi, India)

- Group IV: Prodesign Pediatric rotary file dual taper (Reeganz Dental Care Pvt. Ltd) was used till the working length using an X-Smart motor (Dentsply India Pvt. Ltd., Delhi, India)

- Group V: S2 ProTaper file (Dentsply Maillerfer) was used till the working length using an X-Smart motor (Dentsply India Pvt. Ltd., Delhi, India).

\section{Postoperative volume analysis}

The samples in all the groups were again placed in mounted in vinyl-polysiloxane impression material template (Express ${ }^{\mathrm{TM}}$ XT Putty Quick, 3M ESPE, Germany) in the same position and were subjected to SCT scanning as done for preoperative volume analysis. The volume of each canal in all samples was calculated from the canal orifice to $1 \mathrm{~mm}$ short of apical foramen [Figure 2].

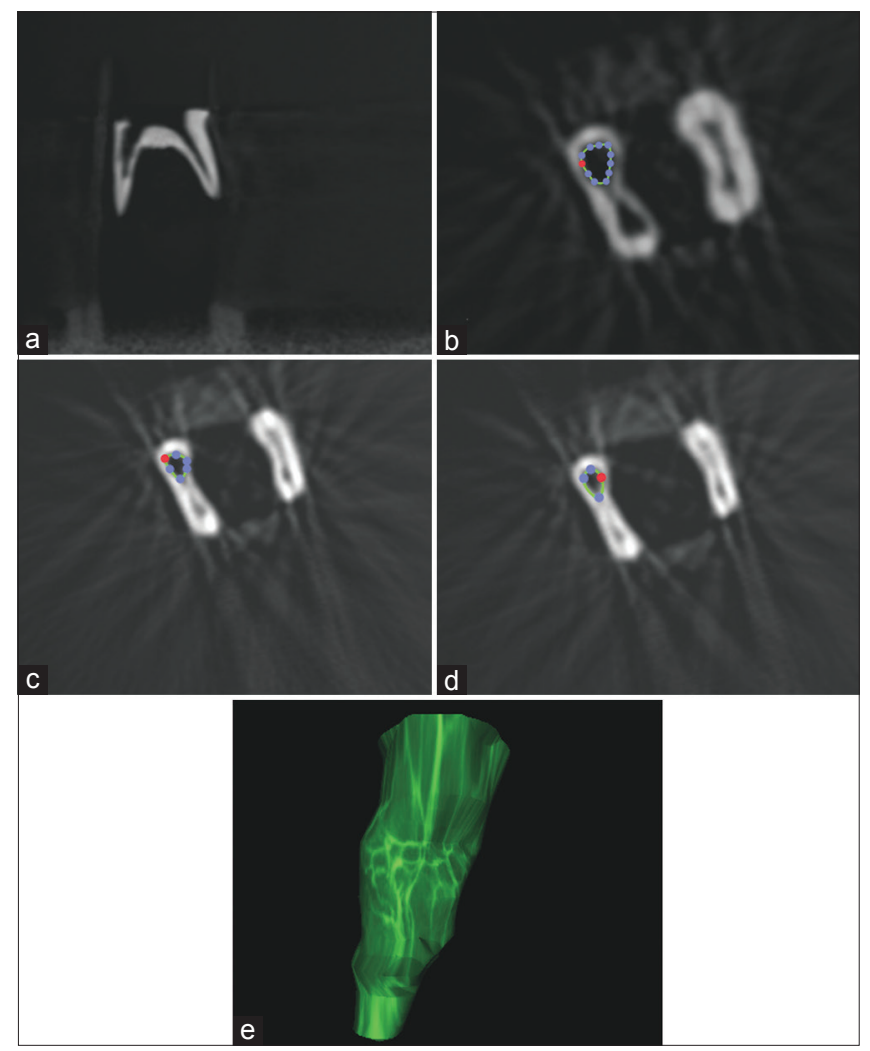

Figure 2: Spiral computerized tomography slice showing (a) primary molar in sagittal view, (b) axial view showing canal volume at coronal third, (c) canal volume at middle third, (d) canal volume at apical third, (e) Three-dimensional view of canal volume from coronal to 1 mm short of apical third

\section{RESULTS}

Statistical analysis was done using SPSS software (17, SPSS Inc., Chicago, IL, USA). The data of preoperative and postoperative canal volume and the difference in canal volume in each canal of all the samples in Groups I-V were calculated and recorded [Table 1]. Intergroup volumetric changes were analyzed statistically by Bonferroni-adjusted Mann-Whitney test [Table 2]. The mean instrumentation time for root canal preparation of all the groups was tabulated [Table 3] and subjected to intergroup statistical analysis using Mann-Whitney U-test [Table 4].

The mean canal volume difference was the highest in Group V (ProTaper files) followed by Group II (Manual files with reciprocating handpiece) and least seen in the Group IV (Prodesign pediatric rotary files). Intergroup comparison of mean canal volume showed statistically significant difference between Groups II versus IV, Groups III versus V, and Groups IV versus V. The highest mean working time was recorded in Group I 194.5 s (manual instrumentation) and least 


\begin{tabular}{|c|c|c|c|c|}
\hline Group & $\begin{array}{c}\text { Average preoperative } \\
\text { volume }\left(\mathrm{cm}^{3}\right)\end{array}$ & $\begin{array}{c}\text { Average postoperative } \\
\text { volume }\left(\mathrm{cm}^{3}\right)\end{array}$ & $\begin{array}{c}\text { Mean volume } \\
\text { difference }\left(\mathrm{cm}^{3}\right)\end{array}$ & $\begin{array}{c}\text { Mean } \\
\text { SD }\left(\mathrm{cm}^{3}\right)\end{array}$ \\
\hline Group I & 0.0058 & 0.0079 & 0.0021 & 0.0006 \\
\hline Group II & 0.0044 & 0.0067 & 0.0025 & 0.0010 \\
\hline Group III & 0.0033 & 0.0048 & 0.0015 & 0.0007 \\
\hline Group IV & 0.0049 & 0.0063 & 0.0014 & 0.0007 \\
\hline Group V & 0.0047 & 0.0075 & 0.0028 & 0.0010 \\
\hline
\end{tabular}

\begin{tabular}{lc} 
Table 2: Intergroup comparison of instrumentation \\
time between groups \\
\hline Groups & $\boldsymbol{P}^{*}$ \\
\hline Group I versus Group II & 0.999 \\
Group I versus Group III & 0.207 \\
Group I versus Group IV & 0.061 \\
Group I versus Group V & 0.253 \\
Group II versus Group III & 0.017 \\
Group II versus Group IV & $0.004^{*}$ \\
Group II versus Group V & 0.999 \\
Group III versus Group IV & 0.999 \\
Group III versus Group V & $0.001^{*}$ \\
Group IV versus Group V & $0.001^{*}$ \\
\hline$P<0.05$ significant &
\end{tabular}

\begin{tabular}{lcc}
\multicolumn{3}{l}{ Table 3: Mean working time for each group in seconds } \\
\hline Groups & Mean & SD \\
\hline Group I & 194.65 & 15.03 \\
Group II & 42.87 & 5.05 \\
Group III & 15.02 & 1.32 \\
Group IV & 11.58 & 0.96 \\
Group V & 11.29 & 0.85 \\
\hline SD. Standard deviation & &
\end{tabular}

SD: Standard deviation

\begin{tabular}{lr}
\multicolumn{2}{l}{ Table 4: Intergroup comparison of instrumentation } \\
time between groups \\
\hline Groups & \multicolumn{1}{c}{$\boldsymbol{P}^{*}$} \\
\hline Group I versus Group II & $0.001^{*}$ \\
Group I versus Group III & $0.001^{*}$ \\
Group I versus Group IV & $0.001^{*}$ \\
Group I versus Group V & $0.001^{*}$ \\
Group II versus Group III & $0.001^{*}$ \\
Group II versus Group IV & $0.001^{*}$ \\
Group II versus Group V & $0.001^{*}$ \\
Group III versus Group IV & $0.001^{*}$ \\
Group III versus Group V & $0.001^{*}$ \\
Group IV versus Group V & $0.291(\mathrm{NS})$ \\
\hline P<0.05 significant, NS: Not significant &
\end{tabular}

was recorded in Group IV 11.29 s (ProTaper files). Intergroup comparison of mean instrumentation time showed statistically significant difference among all the groups except Group IV versus V $(P=0.291)$.

\section{DISCUSSION}

Pulpectomy is a root canal procedure involving complete removal of infected pulpal tissue due to caries or trauma and filling up with a restorable paste. ${ }^{[2]}$ Before the placement of pulpectomy paste, the root canals of primary teeth are cleaned and shaped. ${ }^{[17]}$ Hand instrumentation, including the use of endodontic files and broaches, remains the conventional instrumentation technique for primary teeth and is time-consuming. ${ }^{[18]}$ The advent of Ni-Ti rotary instrumentation has improved root canal treatment by reducing operator fatigue and the preparation time. ${ }^{[19]}$ The flexibility and the instrument design allows the files to closely follow the original root canal path. The tortuous and irregular canal walls of primary molars are effectively cleaned with $\mathrm{Ni}$-Ti files since the clockwise motion of the rotary files pulls the pulp tissue and dentin out of the canal as files are engaged. ${ }^{[4]}$ A major concern of applying protocols for permanent molars to primary molars is that the latter may lead to lateral perforation on the inner root surface, especially in curved primary molar roots. ${ }^{[7]}$ Primary root dentin is softer and less dense than that of the permanent root dentin, and the roots are shorter, thinner, and more curved, often with root tip resorption. ${ }^{[4]}$ A practical pulpectomy technique for the primary teeth should be fast and simple with short treatment time and effective debridement of the root canals without weakening the tooth structure. ${ }^{[2]}$ Hence, the study was carried out to investigate if the hand files in reciprocating motion, rotary Ni-Ti files (RaCe, Prodesign Pediatric rotary file and ProTaper) can be a suitable alternative to Ni-Ti K-Hand files in the root canal preparation of primary molars, by comparatively evaluating the root canal volume, working time, and lateral perforation.

Many studies have used rotary files in extracted human permanent molars. ${ }^{[18,19,21,22]}$ Some studies focused on resin block models, ${ }^{[23-25]}$ and only a few studies were done in primary teeth. ${ }^{[4,10,20,22,25]}$ In the current study, there was a significant increase in root 
canal volume in primary molars with ProTaper files, followed by Ni-Ti K-files in reciprocating motion. The results were in accordance with the findings of N. M Akhlaghi, who evaluated and compared canal preparation pattern of K3 and ProTaper rotary files in curved-resin blocks. ${ }^{[23]}$ Predesigned pediatric rotary files consist of 0.25 tip diameter with $2 \%$ taper from $\mathrm{D}_{0}-\mathrm{D}_{7}$ and $4 \%$ taper from $\mathrm{D}_{8}-\mathrm{D}_{16}$. The present study revealed 0.25 tip $2 \%$ taper file could not produce sufficient apical preparation in primary molars. Prabhakar et al. evaluated the shaping ability of reciprocating single file system with rotary instrumentation and concluded that reciprocating files were faster and safer for root canal preparation. ${ }^{[26]}$ Comparatively, in the current study, rotary instrumentation technique was found to be faster for canal preparation. Our results revealed that rotary instrumentation had less working time than manual and reciprocating of which instrumentation with ProTaper rotary files had shortest working time followed by Prodesign pediatric rotary files. The results are in accordance with the studies done by different authors using various rotary files. ${ }^{[21,27]}$ SCT scanning at various levels of primary mandibular molars revealed that the root canal anatomy varied from round to oval. The canals were wider buccolingually in the shape of ribbon in both mesial and distal canals. ${ }^{[28]}$ On evaluating the root canal morphology of primary mandibular molars, 0.25 tip $4 \%$ taper file is required for adequate canal preparation in apical and middle thirds whereas, in coronal one third, 0.25 tip $6 \%$ taper file will aid in better canal preparation. Recently, an exclusive Ni-Ti rotary file (Kedo-S) has been introduced for root canal preparation of primary teeth with variably variable taper. ${ }^{[29]}$ Besides, considering the internal anatomical configuration of primary molars with accessory canals, copious irrigation is required for complete removal of necrotic pulpal tissue. Therefore, in primary teeth, minimal mechanical preparation with adequate irrigation (Cleaning-Shaping-Irrigation technique) will aid in successful root canal treatment.

\section{CONCLUSION}

With the use of different canal instrumentation techniques in primary teeth: rotary instrumentation technique was found to be efficient for root canal preparation in primary teeth compared to manual and reciprocating techniques.

\section{Financial support and sponsorship} Nil.

\section{Conflicts of interest}

There are no conflicts of interest.

\section{REFERENCES}

1. Kim S. Modern endodontic practice: Instruments and techniques Dent Clin North Am 2004;48:1-9.

2. McDonald RE, Avery DR. Dentistry for the Child and Adolescent. $7^{\text {th }}$ ed. St. Louis: Mosby; 2000. p. 401.

3. Cohen S, Hargreaves KM. Pathways of the Pulp. $9^{\text {th }}$ ed. St. Louis: Mosby; 2006. p. 301-11.

4. Barr ES, Kleier DJ, Barr NV. Use of nickel-titanium rotary files for root canal preparation in primary teeth. Pediatr Dent 2000;22:77-8.

5. Endo MS, Ferraz CC, Zaia AA, Almeida JF, Gomes BP. Quantitative and qualitative analysis of microorganisms in root-filled teeth with persistent infection: Monitoring of the endodontic retreatment. Eur J Dent 2013;7:302-9.

6. Rabinowitch BZ. Pulp management in primary teeth. Oral Surg Oral Med Oral Pathol 1953;6:542-50.

7. Crespo S, Cortes O, Garcia C, Perez L. Comparison between rotary and manual instrumentation in primary teeth. J Clin Pediatr Dent 2008;32:295-8.

8. Nagaratna PJ, Shashikiran ND, Subbareddy VV. In vitro comparison of NiTi rotary instruments and stainless steel hand instruments in root canal preparations of primary and permanent molar. J Indian Soc Pedod Prev Dent 2006;24:186-91.

9. Buehler WJ, Gilfrich JV, Wiley RC. An overview of nickel titanium alloy. J Appl Phys 1963;34:1475.

10. Silva LA, Leonardo MR, Nelson-Filho P, Tanomaru JM. Comparison of rotary and manual instrumentation techniques on cleaning capacity and instrumentation time in deciduous molars. J Dent Child (Chic) 2004;71:45-7.

11. Bary Misikant L. Deep Understanding of Endodontic Mechanics (Online); 2005. Available from: http://www.endomail. com/articles/blm33deeper.htm. [Last accessed on 2009 Oct 19].

12. Varela-Patino F, Martin Biedma B, Rodriguez Nogueira J. Fracture rate of nickel- titanium instruments using continous versus alternating rotation. Endod Pract Today 2008;2:193-7.

13. Yared G. Canal preparation using only one Ni-Ti rotary instrument: Preliminary observations. Int Endod J 2008;41:339-44.

14. Gluskin AH, Brown DC, Buchanan LS. A reconstructed computerized tomographic comparison of Ni-Ti rotary GT files versus traditional instruments in canals shaped by novice operators. Int Endod J 2001;34:476-84.

15. Reuben J, Velmurugan N, Kandaswamy D. The evaluation of root canal morphology of the mandibular first molar in an Indian population using spiral computed tomography scan: An in vitro study. J Endod 2008;34:212-5.

16. Ochoa-Romero T, Mendez-Gonzalez V, Flores-Reyes $\mathrm{H}$, Pozos-Guillen AJ. Comparison between rotary and manual techniques on duration of instrumentation and obturation times in primary teeth. J Clin Pediatr Dent 2011;35:359-63.

17. Chan AW, Cheung GS. A comparison of stainless steel and nickel-titanium K-files in curved root canals. Int Endod J 1996;29:370-5.

18. Ahlquist M, Henningsson O, Hultenby K, Ohlin J. The effectiveness of manual and rotary techniques in the cleaning of root canals: A scanning electron microscopy study. Int Endod J 2001;34:533-7.

19. Peters OA, Peters CI, Schönenberger K, Barbakow F. ProTaper rotary root canal preparation: Effects of canal anatomy on final shape analysed by micro CT. Int Endod J 2003;36:86-92.

20. Madan N, Rathnam A, Shigli AL, Indushekar KR. K-file vs. ProFiles in cleaning capacity and instrumentation time in primary molar root canals: An in vitro study. J Indian Soc Pedod Prev Dent 2011;29:2-6.

21. Aguiar CM, Câmara AC. Radiological evaluation of the morphological changes of root canals shaped with ProTaper for hand use and the ProTaper and RaCe rotary instruments. Aust Endod J 2008;34:115-9.

22. Vaudt J, Bitter K, Neumann K, Kielbassa AM. Ex vivo study on root canal instrumentation of two rotary nickel-titanium systems in comparison to stainless steel hand instruments. Int Endod J 2009;42:22-33.

23. Mohammadzade Akhlaghi N, Khalilak Z, Baradaran Mohajeri L, Sheikholeslami M, Saedi S. Comparison of canal preparation pattern 
of K3 and ProTaper rotary files in curved resin blocks. Iran Endod J 2008;3:11-6.

24. Yoshimine $\mathrm{Y}$, Ono $\mathrm{M}, \mathrm{Akamine} \mathrm{A}$. The shaping effects of three nickel-titanium rotary instruments in simulated S-shaped canals. J Endod 2005;31:373-5.

25. Kuo CI, Wang YL, Chang HH, Huang GF, Lin CP, Ming Li U, et al. Application of Ni-Ti rotary files for pulpectomy in primary molars. J Dent Sci 2006;1:10-5.

26. Prabhakar AR, Yavagal C, Dixit K, Naik SV. Reciprocating vs. rotary instrumentation in pediatric endodontics: Cone beam computed tomographic analysis of deciduous root canals using two single-file systems. Int J Clin Pediatr Dent 2016;9:45-9.

27. Bahrololoomi $\mathrm{Z}$, Tabrizizadeh $\mathrm{M}$, Salmani L. In vitro comparison of instrumentation time and cleaning capacity between rotary and manual preparation techniques in primary anterior teeth. J Dent 2007;4:59-62.

28. Zoremchhingi, Joseph T, Varma B, Mungara J. A study of root canal morphology of human primary molars using computerised tomography: An in vitro study. J Indian Soc Pedod Prev Dent 2005;23:7-12.

29. Jeevanandan G. Kedo-S paediatric rotary files for root canal preparation in primary teeth - Case report. J Clin Diagn Res 2017;11:ZR03-5. 